\title{
PRODUÇÃO DO CONHECIMENTO NA EDUCAÇÃO SUPERIOR AUSTRALIANA: DO ACADÊMICO AO COMERCIAL*
}

\author{
V. LynN MeEK*
}

\begin{abstract}
RESUMO: Este artigo analisa o impacto que as políticas públicas australianas para a educação superior tiveram sobre a pesquisa e a produção de conhecimento nas universidades desse país. A tendência política desses últimos anos levou a educação superior à competição de mercado, à diversificação dos orçamentos e à mercadorização do conhecimento. Isso provocou uma redefinição do valor da pesquisa universitária em termos comerciais e desvalorizou as pesquisas de algumas áreas tradicionais. Este artigo argumenta que, embora o fato de a educação superior ter se adaptado ao mercado tenha tido aspectos positivos, a política do governo, ideologicamente comprometido com a privatização quase completa do setor da educação superior pública, não é do interesse da nação no longo prazo.

Palavras-chave: Políticas de pesquisa. Comercialização. Economia do conhecimento. Condução do mercado. Gestão de pesquisa.
\end{abstract}

\section{FROM ACADEMIC TO COMMERCIAL KNOWLEDGE PRODUCTION IN AUSTRALIAN HIGHER EDUCATION}

ABSTRACT: This paper examines the impact of national higher education policy on research and knowledge production in Australian universities. The policy trend in recent years has been towards market competition, budget diversification and commodification of knowledge. This has helped re-define the value of university research in commercial terms and devalued research in some traditional areas. The paper argues that while there have been positive aspects

Tradução de Alain François.

** Professor e diretor do Centre for Higher Education Management and Policy (Centro de Gestão e Política de Educação Superior) da University of New England (Austrália). E-mail: vmeek@pobox.une.edu.au 
Produção do conhecimento na educação superior australiana...

to the market coordination of higher education, government policy that is ideologically committed to the near total privatisation of a public higher education sector is not in the long-term interests of the nation.

Key words: Research policies. Commercialization. Knowledge economy. Market steering. Research management.

\section{Introdução}

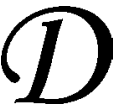

urante a maior parte do século passado, a educação superior plasmou-se pelas normas da ciência, da democracia e pela necessidade de uma cidadania escolarizada, da preservação cultural e de uma elite burocrática bem formada. Entretanto, com o advento da chamada economia do conhecimento/sociedade do conhecimento, políticos, industriais e até mesmo alguns acadêmicos passaram a ver a educação superior não apenas como geradora e difusora de conhecimentos, mas também como "um importante agente de crescimento econômico: a fábrica de conhecimentos, por assim dizer, no centro da economia do conhecimento" (The Economist, 1997). Segundo Scott (1997), "os sistemas de educação superior não são mais simples instituiçôes de 'conhecimento', que reproduzem os recursos intelectuais e humanos exigidos pela sociedade industrial; estão se transformando em instrumentos-chave da reflexividade que define a condição pós-industrial (e pós-moderna)".

O crescente reconhecimento da importância da produção de conhecimento e da formação de uma mão-de-obra altamente qualificada para determinar a posição de uma nação numa economia global baseada no conhecimento, por um lado, aumenta a importância das instituições de educação superior, mas, por outro, ameaça muitos de seus valores tradicionais. Como disse Oliveira $(2002$, p. 1), "existe uma diferença fundamental entre 'ciência como busca da verdade' e 'ciência como atendimento de interesses econômicos e políticos'”. O caráter variável da produção de conhecimento e a gestão da pesquisa nas universidades australianas são um bom exemplo de como novas percepções da utilidade da pesquisa estão estabelecendo novas normas para o mundo acadêmico.

Este artigo começa por um breve esboço do background do sistema australiano de educação superior e do papel que a pesquisa e o de- 
senvolvimento (P\&D) nele desempenham. A seguir, apresenta um resumo das principais revisões políticas, e de suas recomendações, que ajudaram a moldar a estrutura e as características da pesquisa acadêmica nestes últimos dez anos. Finalmente, conclui com uma discussão e análise dos resultados de várias implementaçôes políticas e dos problemas que levantam.

\section{Background da educação superior australiana}

Embora, em termos de superfície, a Austrália seja o sexto maior país do mundo - tem aproximadamente o mesmo tamanho que a parte continental dos Estados Unidos -, sua população é apenas ligeiramente superior à da Holanda. A maior parte dos 20 milhões de habitantes $(0,3 \%$ da população mundial) é altamente urbanizada. "A economia do país representa 1,9\% do Produto Interno Bruto da OCDE, e é responsável por aproximadamente $1 \%$ do comércio mundial" (DEST [Ministério da Educação, da Ciência e da Formação], 2003, p. 3). No passado, a riqueza da nação dependia de produtos primários - minérios e agricultura. Entretanto, nestas últimas décadas, houve uma tentativa deliberada por parte do governo e da indústria de mudar a base da economia australiana dos produtos primários para o conhecimento de criar o que, nos anos de 1980, um primeiro-ministro chamou de um "país inteligente". Ao passo que no começo dos anos de 1970, a indústria representava aproximadamente $21 \%$ do PIB australiano e a agricultura $5,4 \%$, hoje esses números passaram para $12 \%$ e $3,6 \%$, respectivamente. Como disse o diretor econômico (chief economist) de um dos maiores bancos do país: "O crescimento econômico da Austrália será cada vez mais vinculado à beca e menos à lá de carneiro (...)" (The Sydney Morning Herald, 2004).

Até o fim dos anos de 1980, quase todos os recursos monetários da educação superior australiana provinham do governo federal. Entretanto, no fim daquela década, o então governo trabalhista admitiu que não podia financiar sozinho a expansão substancial da educação superior que se tornava necessária. Se no começo dos anos de 1980 as fontes não-governamentais de financiamento para a educação superior eram insignificantes, hoje várias universidades, especialmente as mais antigas e mais bem estabelecidas, recebem mais da metade (algumas até quase $75 \%$ ) de sua receita operacional de fontes não-governamentais. A par- 
Produção do conhecimento na educação superior australiana...

ticipação da União na receita total das universidades caiu de $57,2 \%$ em 1995 para 43,8\% em 2001 (Phillips et al., 2003, p. 33). Em média, em torno de um terço do orçamento das universidades provém de receitas próprias. Foi um governo trabalhista que, no fim dos anos de 1980, acabou introduzindo essa tendência de maior diversificação do financiamento da educação superior australiana. $\mathrm{O}$ atual governo de coalizão liberal, que chegou ao poder em 1995, acelerou essa tendência reduzindo, em termos reais, a participação financeira direta da União na educação superior e aumentando substancialmente o ônus financeiro assumido pelos alunos (Tabela 1).

\section{Tabela 1}

Receita das universidades por fonte 1995-2001 (\$B)

(valores ajustados pelo Índice de Preços ao Consumidor [CPI] de 2000)

\begin{tabular}{|l|c|c|c|c|c|c|c|c|}
\hline & 1995 & 1996 & 1997 & 1998 & 1999 & 2000 & 2001 & $\begin{array}{c}\text { Variação } \\
(\%)\end{array}$ \\
\hline União & 5,0 & 5,1 & 4,9 & 4,7 & 4,6 & 4,5 & 4,5 & $-9,9$ \\
HECS* & 1,0 & 1,0 & 1,3 & 1,6 & 1,8 & 1,8 & 1,8 & 70,5 \\
Mensalidades & 1,0 & 1,2 & 1,4 & 1,5 & 1,7 & 1,8 & 2,0 & 99,3 \\
Estados & 0,1 & 0,1 & 0,1 & 0,1 & 0,1 & 0,2 & 0,2 & 49,0 \\
Outros & 1,5 & 1,5 & 1,4 & 1,4 & 1,4 & 1,7 & 1,8 & 14,1 \\
Total & 8,7 & 9,0 & 9,2 & 9,4 & 9,6 & 9,9 & 10,2 & 17,6 \\
\hline
\end{tabular}

Fonte: Phillips et al., 2003, p. 32.

* Higher Education Contribution Scheme (Programa de Contribuição para a Educação Superior - pago por estudantes australianos)

Em contrapartida, o número de alunos da educação superior australiana, que era de aproximadamente 485 mil em 1990, praticamente duplicou em 2004. Ora, nestes últimos anos, o aumento do número de estudantes se deveu essencialmente ao ingresso de estudantes estrangeiros que pagam mensalidades integrais. De fato, entre 1995 e 2001, o número de alunos ingressantes australianos aumentou em $8,6 \%$, ao passo que o número de alunos ingressantes estrangeiros aumentou em 146\% (Phillips et al., 2003, p. 11). O crescimento lento do número de estudantes australianos não indica uma queda na demanda, mas uma falta de vagas para satisfazê-la. 
A situação dramática do financiamento da educação superior australiana chama cada vez mais a atenção pública. O financiamento concentrado no aluno na base do sistema de cheque-ensino era a principal recomendação da Review of Higher Education Financing and Policy (Revista de Financiamento e Política para a Educação Superior), em abril de 1998. Em 2000 e 2001, o governo introduziu algumas políticas que afetaram diretamente o financiamento de pesquisas, pois se comprometia a aumentar o financiamento de pesquisas num período de dez anos (ver Backing Australia's ability, 2001). Em 2002, o governo federal realizou um levantamento das universidades australianas chamado "Higher education at the crossroads" (A educação superior na encruzilhada). Não obstante, os muitos levantamentos (position statements) e as numerosas reaçóes do setor e dos governos estaduais, a política do governo federal foi anunciada como um mero fait accompli (fato consumado) no demonstrativo orçamentário (budget statement) de 2003. Embora trouxesse uma promessa de dinheiro novo, essa política mantinha a tendência básica rumo a maior privatização do financiamento da educação superior por meio do aumento das mensalidades, e permitia que as instituições fixassem o valor de suas próprias mensalidades (dentro de um certo patamar) e que pudessem matricular um número maior de alunos de graduação australianos pagando mensalidade integral. Como explicaremos mais detalhadamente abaixo, essas políticas exerceram uma pressão ainda maior sobre as universidades para que elas se tornassem mais empresariais e colhessem os benefícios comerciais de suas produções acadêmicas.

\section{Pesquisa}

A Austrália tem uma base científica bem desenvolvida, mas comparativamente pequena, e a maioria de seus esforços de P\&D concentrase no setor público. Se considerarmos o tamanho do país, a contribuição da Austrália à ciência mundial é impressionante, particularmente no que diz respeito às disciplinas de medicina e saúde, às ciências biológicas e à astronomia. Segundo dados de 2002, a Austrália:

- contribuiu com 2,88\% das pesquisas publicadas no mundo (incluindo ciências, ciências sociais e humanas) contra 2,3\% em 1988; 
Produção do conhecimento na educação superior australiana...

- ocupava a nona posição, entre 21 países, em número total de publicações científicas, atrás apenas de Estados Unidos, Japão, Reino Unido, Alemanha, França, Canadá, Itália e Espanha, e à frente de países como Holanda, Suécia, Suíça e Coréia;

- ocupava a oitava posição, entre 21 países, em número de publicações científicas per capita, à frente de Estados Unidos, Canadá, Alemanha, França e Japão, e atrás de Suíça, Suécia, Israel, Dinamarca, Finlândia, Holanda e Reino Unido (DEST, 2003, p. 6).

Por várias razões históricas e geográficas, o financiamento da área de P\&D na Austrália depende muito mais dos cofres públicos que o da maioria dos outros países desenvolvidos. Em contraste, os dispêndios empresariais em P\&D (DEPD) são baixos se comparados com os dos outros países da OCDE. Isso se deve principalmente ao fato de a maior parte das grandes multinacionais terem suas sedes fora da Austrália e se envolverem pouco com P\&D nesse país. Diferentemente dos EUA e do Reino Unido, existem poucas fundações privadas, às quais os australianos possam recorrer para financiar suas pesquisas, e o apoio de fundos de fomento, do qual desfrutam algumas das maiores universidades americanas, inexiste por completo. Em 2001, os DEPD da Austrália representaram, em porcentagem de PIB, menos de metade da média de 1,62\% dos países da OCDE (DEST, 2003, p. 25). A Austrália também fica bastante aquém de muitos outros países da OCDE em termos de dispêndios em P\&D em porcentagem do PIB - as despesas totais da Austrália são de 1,53\% do PIB contra uma média de 2,25\% na OCDE.

O nível relativamente baixo de investimento do setor privado em $P \& D$ levou o governo a desempenhar um papel preponderante no financiamento da ciência e da inovação tecnológica australianas. $O$ governo federal canaliza seu apoio à área de $\mathrm{P} \& \mathrm{D}$ por intermédio de vários programas e organizaçōes, sendo os dois maiores a Commonwealth Scientific and Industrial Research Organisation (CSIRO - Organização para a Pesquisa Científica e Industrial da União) e as universidades nacionais, a primeira recebendo diretamente do governo aproximadamente $\$ 612$ milhões e as segundas, \$6.652 milhões. Obviamente, os fundos da União para as universidades dividem-se entre ensino e pesquisa. Além do mais, na Austrália, muito mais pessoas das que trabalham com $P \& D$ se encontram na educação superior do que na maioria dos países da OCDE. 
A Tabela 2 fornece uma idéia geral das despesas das universidades em P\&D por fonte de financiamento. Um aspecto interessante é o aumento constante, embora leve, das despesas em $P \& D$ provenientes de governos estaduais e municipais. Como dissemos acima, em 1974, a União assumia quase todo o financiamento da educação superior, sendo quase insignificantes tanto os investimentos quanto a influência política dos governos estaduais na educação superior. Ora, ao longo destes últimos anos, alguns estados retomaram o financiamento das universidades, mais particularmente nas áreas das biotecnologias, na crença de que esses investimentos haveriam de consolidar a economia local - uma aposta clara na noção de economia do conhecimento. Com esse intuito, vários estados criaram conselhos de ciência e inovação: Queensland's Smart State; Victoria's Science, Technology and Innovation Initiative; New South Wale's BioFirst Strategy; e Western Austrália's Innovate WAPolicy.

\section{Tabela 2}

Despesas das universidades em pesquisa e desenvolvimento experimental por fonte de financiamento - 1988-2000

\begin{tabular}{|l|c|c|c|c|c|c|c|}
\hline Fonte de Financiamento & 1988 & 1990 & 1992 & 1995 & 1996 & 1998 & 2000 \\
\hline Governo da União & & & & & & & \\
\hline Fundos gerais das universidades & & & & $66,1 \%$ & $65,4 \%$ & $63,7 \%$ & $62,9 \%$ \\
\hline Programas da União & & & & $16,9 \%$ & $16,3 \%$ & $16,6 \%$ & $17,4 \%$ \\
\hline Outras fontes da União & & & & $6,6 \%$ & $7,0 \%$ & $7,4 \%$ & $6,4 \%$ \\
\hline Total da União & $91,3 \%$ & $88,4 \%$ & $91,1 \%$ & $89,6 \%$ & $88,7 \%$ & $87,7 \%$ & $86,8 \%$ \\
\hline Governos estaduais e municipais & $1,5 \%$ & $2,5 \%$ & $2,1 \%$ & $2,2 \%$ & $2,2 \%$ & $2,7 \%$ & $3,2 \%$ \\
\hline Empresas comerciais & $2,6 \%$ & $2,2 \%$ & $2,5 \%$ & $4,7 \%$ & $5,2 \%$ & $5,2 \%$ & $4,9 \%$ \\
\hline Outras fontes australianas & $3,9 \%$ & $6,2 \%$ & $3,7 \%$ & $2,5 \%$ & $2,8 \%$ & $2,9 \%$ & $3,0 \%$ \\
\hline Fontes estrangeiras & $0,7 \%$ & $0,7 \%$ & $0,6 \%$ & $1,1 \%$ & $1,1 \%$ & $1,6 \%$ & $2,2 \%$ \\
\hline
\end{tabular}

Fonte: AVCC, 2003a, p. 6. 
Produção do conhecimento na educação superior australiana...

\section{Política de pesquisa na educação superior}

$\mathrm{Na}$ Austrália, como em outros lugares, a pesquisa universitária era tradicionalmente realizada no contexto de uma estrutura disciplinar, situando-se, suposta ou realmente, no nível mais elementar da grade de pesquisas. É fato, entretanto, que, nesta última década, a relevância da pesquisa universitária foi questionada e houve pressōes para torná-la mais significativa em termos econômicos.

As tendências no financiamento público da educação superior, as pressões para a comercialização da produção intelectual gerada pela universidade, as novas abordagens para a gestão da pesquisa nas empresas, as mudanças na cultura de aprendizagem, e o crescimento das indústrias de alta tecnologia em pequenas empresas levaram ao surgimento de novas formas de pesquisa que exigiam relações de trabalho mais estreitas entre as pessoas de diferentes disciplinas e profissóes (...) (DEST, 2003, p. 118).

A estratégia do governo australiano para produzir conhecimento é essencialmente utilitária e focaliza a comercialização e o retorno econômico. Em geral, as administraçôes das universidades tendem a traduzir as diretrizes e prioridades das políticas governamentais para a pesquisa em práticas institucionais. Da maneira como está evoluindo hoje em dia a gestão da pesquisa, tende-se a dividir tanto as instituiçôes quanto o setor como um todo em "ricos da pesquisa" e "pobres do ensino". Para entender plenamente as implicaçôes das atuais práticas políticas e de gestão da pesquisa, é preciso entrar mais a fundo no seu funcionamento.

Por mais de uma década, os governos federais têm estimulado a competição entre instituiçôes, particularmente no que diz respeito ao financiamento de pesquisas. O Plano Diretor de 1988 (Higher education: a policy statement [Educação superior: um posicionamento político]), que lançou os fundamentos da reforma da educação superior australiana, afirmava que a "concentração e a seletividade nas pesquisas são necessárias para se ter um financiamento plenamente eficiente" (p. 90). Para acirrar ainda mais a competição em torno do financiamento de pesquisas, o governo federal lançou, em junho de 1999, um texto para discussão sobre pesquisa e formação para pesquisa, intitulado New knowledge, new opportunities (Novos conhecimentos, novas oportunidades). Esse texto apontava para o que considerava várias deficiências no quadro atual, as quais estariam limitando a capacidade das instituiçóes de 
responder aos desafios da emergente economia do conhecimento: incentivos ao financiamento que não encorajam suficientemente a diversidade e a excelência; conexões fracas entre pesquisa acadêmica e o sistema australiano de inovação; falta de concentração por instituições de áreas não muito fortes; deficiência profissional dos alunos formados para pesquisa; e desperdício inaceitável de recursos associado a um baixo índice de formados e uma duração exagerada do tempo de formação. Uma preocupação particular do governo era a formação para a pesquisa e o financiamento de alunos pesquisadores em doutorado e mestrado.

Em dezembro de 1999, o governo publicou seu projeto de políticas para a área de pesquisa e formação para pesquisa, Knowledge and innovation [Conhecimento e inovação] que assinalava importantes mudanças no âmbito da política e do financiamento da pesquisa na educação superior australiana. A recomendação mais importante do documento-base para a gestão da pesquisa nas universidades dizia respeito ao aumento da concorrência para o financiamento de pesquisas, particularmente para as bolsas de alunos pesquisadores em doutorado e mestrado.

Knowledge and innovation instituía dois novos programas de financiamento baseados no desempenho que objetivavam recompensar "as instituições que põem à disposição ambientes de formação para pesquisas de alta qualidade e apóiam atividades de pesquisa diversas e de excelência”. Supostamente, o Institutional Grants Scheme (IGS - Programa de Subvençóes Institucionais [PSI]) "ampararia a maioria das pesquisas das instituiçõoes e as atividades de formação para pesquisa, e ajudaria as instituições a responder de maneira flexível a seu meio, de acordo com suas próprias orientações estratégicas" (Gallagher, 2000).

O PSI aloca os fundos com base numa fórmula que leva em conta o sucesso em atrair recursos para pesquisa de fontes diversas (60\%), atrair alunos pesquisadores $(30 \%)$ e garantir a qualidade e a produção de publicações de pesquisa, quantificadas a partir de um critério de revisão $(10 \%)$. O governo supunha que as instituições orientariam suas pesquisas mais para fora se as fontes dos financiamentos fossem mais equilibradas, ao contrário do que acontecia antes, quando os recursos vindos das indústrias tinham um peso menor (Gallagher, 2000).

O financiamento da formação para pesquisa (RTS) também angaria recursos a partir de uma fórmula baseada no desempenho. As insti- 
Produção do conhecimento na educação superior australiana...

tuições vão atrair um número de vagas para bolsistas em função de seu desempenho calculado com base numa fórmula que compreende três elementos: número total de alunos pesquisadores que se formam $(50 \%)$, rendimento da pesquisa $(40 \%)$ e quantidade das publicações $(10 \%)$.

As mudanças no sistema de financiamento da pesquisa exigiram que as universidades australianas repensassem profundamente sua forma de gestão da pesquisa e de formação de pesquisadores. Os pontos importantes da agenda eram a necessidade de identificar prioridades, de concentrar os esforços de pesquisa, e de desenvolver um conjunto de indicadores de desempenho e sistemas sofisticados de informaçóes sobre a gestão da pesquisa.

Além de introduzir novos mecanismos de financiamento da pesquisa, o governo interferiu no estabelecimento de prioridades para a pesquisa. No início de 2002, anunciou, como resultado de um processo de "consulta" pouco transparente, que parte (33\%) dos financiamentos do Australian Research Council (Conselho de Pesquisa Australiano, a maior agência de financiamento de pesquisa não-médica da Austrália) seria destinada para pesquisas nas seguintes quatro áreas prioritárias: nanomateriais e biomateriais, genoma/fenoma, sistemas complexos/inteligentes, e ciência e tecnologia de fótons.

Em maio de 2002, o governo criou um processo de revisão para melhor determinar as prioridades nas pesquisas australianas a serem financiadas pelo governo nas áreas de ciência e engenharia. Segundo o governo, as prioridades "vão destacar áreas de pesquisa de particular importância para a economia e a sociedade australianas, nas quais a atenção de todo o governo pode melhorar a pesquisa e ampliar os resultados políticos" (DEST, 2002, p. 1). Anunciadas no fim de 2002, essas prioridades eram: uma Austrália ambientalmente sustentável; promover e manter uma boa saúde; desenvolver tecnologias de fronteira para construir e transformar as indústrias australianas; defender os interesses da Austrália.

Ao iniciar o processo de revisão das prioridades, pretendia-se estender o estabelecimento de prioridades de pesquisa das ciências e engenharias também às ciências sociais e humanas. Isso não ocorreu. Ao contrário disso, foram determinadas submetas para cada área prioritária de modo que as ciências sociais e humanas pudessem ser incorporadas. 
Entretanto, embora muito abrangentes, essas prioridades favorecem as ditas "ciências duras" e enfatizam principalmente áreas de relevância econômica imediata. Todos os organismos de pesquisa e todas as agências de financiamento da União devem respeitar essas prioridades de pesquisa.

\section{Discussão e análise}

O problema mais crucial que a educação superior australiana em geral e a pesquisa em particular enfrentam continua sendo, obviamente, o financiamento. Contudo, está em jogo muito mais do que apenas dinheiro. No cerne do problema encontra-se a questão de saber se a Austrália deve ter um sistema de educação superior financiado com recursos públicos, ou um sistema inteiramente particular. Embora, na presente rodada de reformas, o governo tenha anunciado recursos novos para o setor, a maior parte deles será absorvida pela atual série de reajustes salariais que resultaram das negociações salariais empresariais. Além do mais, como mencionamos anteriormente, a principal reforma do financiamento, adotada pelo governo, visou a aumentar mais ainda o ônus que recai sobre os estudantes consumidores. Seja como for, essas mensalidades não irão promover um aumento do rendimento da pesquisa. De fato, com uma proporção professores/alunos cada vez pior, algumas universidades usam o retorno financeiro dos trabalhos de pesquisa para financiar o ensino via pagamento de salários de professores.

O governo ainda deve enfrentar sérias questōes de financiamento em termos estruturais e de longo prazo. Quanto mais tempo se deixa a infra-estrutura de pesquisa à míngua, mais difícil fica para a nação recuperar sua posição de $\mathrm{P} \& \mathrm{D}$ com relação ao resto do mundo. Um expresidente do Australian Vice-Chancellor's Committee (AVCC) observa que "se o ritmo das mudanças em investimento público nas universidades for tal que nossas universidades irão ficar muito aquém das de outros países, não conseguiremos mais recuperar o terreno perdido" (Chubb, 2000, p. 3). Ele ainda se mostrou preocupado com o fato de que "a Austrália irá se tornar um importador de conhecimento e um exportador de talentos e teremos muito pouco pessoal escolarizado, em nível local, para agregar valor à produção dos outros, quanto menos para produzirmos nós mesmos". Como mostramos antes, embora o esforço de pesquisa australiano dependa mais do fomento público do que 
Produção do conhecimento na educação superior australiana...

na maioria dos países-membros da OCDE, o compromisso ideológico do governo orientou-se para o mercado e a privatização.

Uma questão importante na pesquisa acadêmica australiana é a conexão entre ensino e pesquisa. Nenhum país pode dar-se ao luxo de financiar todas as suas universidades como se fossem instituições excepcionais de pesquisa de ponta. Em contrapartida, há quem argumente que todo o ensino universitário deve ser impulsionado por pesquisas. Além do mais, cada instituição tem seus próprios argumentos especiais para justificar por que deveria ser reconhecida como uma universidade de pesquisa de ponta (independentemente de os fatos confirmarem ou não tais argumentos). O colapso do sistema binário de educação superior no começo dos anos de 1990 exacerbou esse problema. A introdução de novas medidas de financiamento, baseadas no desempenho em termos de pesquisa (RTS e PSI), mencionadas anteriormente, foi planejada com o objetivo de concentrar o financiamento nos centros de pesquisa. Ainda é cedo para dizer se essas políticas terão o efeito desejado, pois, até 2005 , foi fixado um teto para os financiamentos que cada universidade pode perder ou ganhar mediante a aplicação dessas políticas. Entretanto, num prazo mais longo, o governo pode considerar que políticas mais radicais se tornem necessárias.

Com políticas de pesquisa fortemente baseadas em princípios de concentração e de seletividade, não surpreende que o governo australiano deseje priorizar certas áreas de pesquisa. Contudo, se o financiamento for se concentrando paulatinamente em algumas áreas consideradas prioritárias, corre-se o risco de "imobilizar, por meio de uma camisa de força”, o espírito inovador. Eis um dos dilemas que um pequeno país com uma base científica limitada enfrenta: embora a nação não possa financiar suficientemente todos os tipos e aspectos da pesquisa moderna, ela deve manter uma base científica bastante ampla para participar dos avanços mundiais dos conhecimentos. Segundo o AVCC (2003b, p. 22),

a questão crucial é a pluralidade: como nação, precisamos apoiar uma gama ampla de pesquisas, e fazê-lo por diferentes meios. Permitir que uma única abordagem domine resultaria inevitavelmente numa redução da capacidade de pesquisa de modo geral e num sistema de inovação nacional mais fraco. O impacto da atribuição de prioridades às pesquisas deveria ser reestruturado levando em conta esta fato. 
Um outro aspecto do estabelecimento de prioridades é a preferência dada às ciências (naturais) e às engenharias em detrimento das ciências sociais e humanas. $\mathrm{O}$ presente modelo de prioridades praticamente desconhece as ciências sociais. $\mathrm{O}$ pensamento atual baseia-se essencialmente no pressuposto de que pesquisa que vale a pena significa comercialização e que comercialização significa ciência e tecnologia. Mais uma vez, uma abordagem mais equilibrada é necessária. As ciências sociais têm muito a acrescentar, em particular à prosperidade social e cultural da nação. Elas também devem desempenhar um papel importante como críticas das conseqüências ambientais e sociais de um desenvolvimento científico norteado pela tecnologia. No entanto, com a crescente ênfase na comercialização, a universidade pode ser afastada de seu papel de "dizer a verdade ao poder". Alguns indícios sugerem que este também é um problema grave no setor da educação superior dos Estados Unidos (Newman et al., 2004). Até o AVCC (2003b, p. 12) concorda que "a recente atribuição de prioridades às pesquisas subestimou a contribuiçãa trazida pelas ciências sociais e humanas”.

A pouca ênfase dada à pesquisa básica, com relação à pesquisa aplicada e à de desenvolvimento, também está ligada à questão da atribuição de prioridades. Tanto o governo quanto os gestores institucionais têm se interessado muito pela comercialização dos resultados de pesquisas. Isso provocou ao longo dos anos uma canalização do financiamento da pesquisa básica para a pesquisa aplicada, o que a Tabela 3 confirma claramente. A visão linear da inovação científica não tem mais credibilidade. Contudo, se a pesquisa básica "insignificante" diminui paulatinamente, a fonte de idéias e avanços no conhecimento que alimenta outras formas de pesquisa e inovaçôes tecnológicas também pode secar.

A ênfase na pesquisa aplicada reflete o interesse, tanto do governo quanto dos gestores institucionais, na comercialização dos resultados das pesquisas, o que, por sua vez, favorece o financiamento de pesquisas que geram resultados comercializáveis. Isso parece ter provocado um forte declínio do tipo de pesquisas "não direcionadas" ou "de avanço do conhecimento", como mostra a Tabela 4.

A sociedade continua sendo a maior categoria de pesquisa no que diz respeito aos objetivos socioeconômicos de pesquisa, o que se deve em parte ao fato de a pesquisa em saúde estar incluída nessa categoria. 
Produção do conhecimento na educação superior australiana...

\section{Tabela 3}

Despesas das universidades em pesquisa e desenvolvimento experimental por tipo de atividade de pesquisa - 1988-2000

\begin{tabular}{|l|r|r|r|r|r|r|}
\hline Tipo de Atividade de Pesquisa & 1988 & 1990 & 1992 & 1996 & 1998 & 2000 \\
\hline Pesquisa básica pura & $38,0 \%$ & $41,0 \%$ & $40,0 \%$ & $34,1 \%$ & $33,5 \%$ & $30,5 \%$ \\
Pesquisa básica estratégica & $24,0 \%$ & $22,0 \%$ & $24,0 \%$ & $25,0 \%$ & $25,4 \%$ & $24,0 \%$ \\
Pesquisa aplicada & $31,0 \%$ & $31,0 \%$ & $30,0 \%$ & $34,7 \%$ & $35,0 \%$ & $37,8 \%$ \\
Desenvolvimento experimental & $7,0 \%$ & $6,0 \%$ & $6,0 \%$ & $6,2 \%$ & $6,1 \%$ & $7,7 \%$ \\
\hline Total $(\$ \mathrm{~m})$ & $1.076,8$ & $1.350,8$ & $1.695,2$ & $2.307,6$ & $2.600,2$ & $2.774,6$ \\
\hline
\end{tabular}

Fonte: AVCC, 2003a, p. 7. (Os valores das despesas anuais não foram corrigidos).

\section{Tabela 4}

Objetivos socioeconômicos (OSE) das pesquisas por tipo de financiamento

\begin{tabular}{|c|c|c|c|c|c|c|c|c|c|c|c|c|}
\hline \multirow{2}{*}{$\begin{array}{l}\text { \% Total de P\&D na } \\
\text { Educação Superior } \\
\text { visando a OSE }\end{array}$} & \multicolumn{3}{|c|}{$\begin{array}{l}\text { Desenvolvimento } \\
\text { econômico }\end{array}$} & \multicolumn{3}{|c|}{ Sociedade } & \multicolumn{3}{|c|}{ Meio ambiente } & \multicolumn{3}{|c|}{$\begin{array}{c}\text { Pesquisas } \\
\text { não direcionadas }\end{array}$} \\
\hline & 96 & 98 & 00 & 96 & 98 & 00 & 96 & 96 & 00 & 96 & 98 & 00 \\
\hline Todas as fontes & $21 \%$ & $23 \%$ & $29 \%$ & $25 \%$ & $27 \%$ & $40 \%$ & $7 \%$ & $7 \%$ & $6 \%$ & $46 \%$ & $42 \%$ & $25 \%$ \\
\hline $\begin{array}{l}\text { Financiamentos } \\
\text { competitivos da União }\end{array}$ & $21 \%$ & $24 \%$ & $27 \%$ & $25 \%$ & $26 \%$ & $39 \%$ & $8 \%$ & $7 \%$ & $6 \%$ & $46 \%$ & $43 \%$ & $28 \%$ \\
\hline $\begin{array}{l}\text { Governos estaduais e } \\
\text { municipais }\end{array}$ & $21 \%$ & $27 \%$ & $31 \%$ & $51 \%$ & $47 \%$ & $48 \%$ & $10 \%$ & $9 \%$ & $12 \%$ & $18 \%$ & $17 \%$ & $10 \%$ \\
\hline Negócios & $43 \%$ & $42 \%$ & $44 \%$ & $21 \%$ & $22 \%$ & $32 \%$ & $9 \%$ & $10 \%$ & $7 \%$ & $26 \%$ & $25 \%$ & $16 \%$ \\
\hline $\begin{array}{l}\text { Fundos gerais das } \\
\text { universidades }\end{array}$ & $18 \%$ & $22 \%$ & $28 \%$ & $24 \%$ & $27 \%$ & $40 \%$ & $7 \%$ & $7 \%$ & $5 \%$ & $50 \%$ & $44 \%$ & $27 \%$ \\
\hline Estrangeiro & $23 \%$ & $26 \%$ & $27 \%$ & $36 \%$ & $32 \%$ & $47 \%$ & $6 \%$ & $4 \%$ & $5 \%$ & $33 \%$ & $38 \%$ & $21 \%$ \\
\hline
\end{tabular}

Fonte: AVCC, 2002, p. 3.

A categoria "desenvolvimento econômico" cresce de maneira regular. A tendência mais alarmante é o forte declínio das "pesquisas não direcionadas", ou do que se costuma classificar como "avanços no conhecimento". Os campos que integram essa categoria são: as ciências matemáti- 
cas; as ciências físicas; as ciências químicas; as ciências da terra; as ciências biológicas; as ciências políticas e de políticas públicas; os estudos da sociedade humana; e as ciências comportamental e cognitiva (AVCC, 2002, p. 2). Ao notar o declínio das pesquisas básicas, o AVCC (2003b, p. 19) advertiu que, "sem uma ancoragem forte nas pesquisas básicas puras, o sistema de inovação australiano irá começar a sentir falta de idéias - ou terá de importá-las de outros lugares, a custos cada vez mais elevados. Um investimento garantido e substancial nas pesquisas básicas é decididamente do interesse da Nação".

A concentração e a seletividade são questões cruciais na pesquisa. Isso significa que as universidades devem identificar pontos fortes e tomar decisóes difíceis para alocar recursos em algumas áreas e não em outras. Obviamente, as áreas mais propensas a mercadorizar seus resultados intelectuais vão se beneficiar da maior parte do novo regime de financiamento. Também é bastante óbvio que essas áreas não estão distribuídas aleatoriamente na academia. E, justamente, quem sai ganhando não são a ciência e a tecnologia, mas aqueles subcampos que podem alegar que seus trabalhos trazem, no curto ou médio prazos, retorno econômico. Existe o perigo de que as ciências básicas sejam ainda mais excluídas e de que particularmente as disciplinas tradicionalmente associadas a pesquisas básicas, como a química e a física, declinem mais ainda.

Com a nova fórmula de financiamento das pesquisas para alunos pesquisadores, as universidades recebem recursos não apenas por intermédio das mensalidades, mas também por meio de uma taxa correspondente ao número de formandos. Isso representa uma dificuldade particular para as faculdades de ciências sociais e humanas, uma vez que muitos de seus alunos-pesquisadores costumam estudar em período parcial, necessitando de mais tempo para se formarem. Além do mais, o número de formandos é baixo se comparado com o de outras disciplinas. Embora tenham absorvido grande parte dos financiamentos de formação para pesquisas iniciais (RTS), essas áreas podem ver seu número de estudantes diminuir futuramente se as porcentagens de formados ficarem fora do padrão da fórmula. Para proteger sua parte da cota nacional de estudantes-pesquisadores, uma universidade pode decidir que não tem condições de se dar ao luxo de oferecer certas carreiras no campo das artes, das humanidades e das ciências sociais.

Intencionalmente ou não, os dirigentes das universidades estão jogando o jogo da concentração da pesquisa e da determinação de prio- 
Produção do conhecimento na educação superior australiana...

ridades, com o risco potencial de segmentar os acadêmicos em "ricos da pesquisa" e "pobres do ensino". Se alocarem os financiamentos e as infraestruturas de pesquisa nas áreas prioritárias, as áreas não-prioritárias terão cada vez menos recursos para fazer pesquisas. Esta parece justamente ser a intenção do governo:

Parece estar na hora de desafiarmos os pressupostos do modelo acadêmico em grande parte do século passado, e validar carreiras acadêmicas alternativas. Alguns acadêmicos podem escolher especializar-se em ensino, e se tornarem acadêmicos que "apenas ensinam". Outros podem escolher especializar-se em pesquisa. (Striving for quality [Em busca de qualidade], 2002)

Mais recentemente, o cientista principal do governo australiano, Robin Batterham, pedia uma "separação ainda maior entre o financiamento do ensino e o financiamento da pesquisa”, e teria acrescentado que "bons professores não precisam ser pesquisadores de ponta (...)" (Illing, 2003, p. 21). De modo semelhante, embora com relação à situação do Reino Unido, Willmott (1998, p. 1) argumenta que a

maior importância dos Exercícios de Avaliação de Pesquisa (...) não reside na racionalização dos recursos para a pesquisa ou na garantia de mais responsabilidade nas suas despesas, mas, antes, nas suas contribuiçôes para legitimar a reestruturação da educação superior que tem incluído o corte do financiamento de pesquisas de uma porção cada vez maior de acadêmicos e departamentos.

Nesses dois países, a intenção não é meramente separar pesquisa e ensino, mas vincular a pesquisa mais estreitamente às necessidades da indústria e da economia, reduzindo, ao mesmo tempo, seu custo unitário.

\section{Conclusão}

Bertelsen (2002, p. 1) observa que "a mercadorização da educação superior para servir ao mercado está revolucionando completamente nossa prática, da imagem institucional até a gestão, dos empregos ao currículo". Nas universidades australianas, as administrações de muitas instituições promovem fortemente as áreas que podem trazer lucros e cortam muitos investimentos em atividades menos lucrativas, como as humanidades, as línguas antigas e até mesmo algumas línguas modernas etc. Di- 
ante do declínio do financiamento público e do aumento do número de estudantes num mercado volátil e altamente competitivo, os dirigentes institucionais podem obviamente alegar que não têm outra escolha.

A universidade moderna tem mudado sua orientação do conhecimento social para o conhecimento de mercado e o "desenvolvimento de uma universidade orientada para o mercado está substituindo as tomadas de decisão acadêmicas" (Buchbinder, 1993, p. 335). Segundo Newson (1993, p. 298), "essas novas formas de tomadas de decisão solapam profundamente a concepção de universidade como uma instituição autônoma que se autogoverna e é avaliada por pares com base na autoridade profissional; muda, assim, a política de realização dos trabalhos acadêmicos".

$\mathrm{Na}$ passado, devia-se lealdade acadêmica, primeiro e essencialmente, à disciplina e às normas disciplinares sobre a definição e a produção de conhecimento (Clark, 1983). Com a mercadorização do conhecimento, essa lealdade está ameaçada por grupos poderosos, tanto dentro quanto fora da academia, que exigem lealdade, antes de tudo, para com a instituição - isto é, com a empresa que paga a fatura (Meek, 2003). "As políticas científicas, quer nacional ou internacionalmente, vêm erodindo, em diferentes graus, a autonomia acadêmica desde o começo dos anos de 1970" (Henkel, 2002, p. 58). Henkel ainda afirma que "o divisor de águas aqui é o Relatório Brooks para a OCDE (1971), pois determinou que o estabelecimento de prioridades de pesquisa cabia aos governos e não aos cientistas e que o principal promotor das políticas científicas devia ser a realização de objetivos sociais e econômicos". De modo semelhante, Slaughter \& Leslie (1997, p. 5) argumentam que:

A participação no mercado começou a abalar o contrato tácito entre os professores e a sociedade porque o mercado dá ênfase tanto ao resultado quanto à satisfação do cliente. Tanto a raison d'être [razão de ser] do tratamento especial das universidades (o fato de serem o campo de formação de profissionais) quanto os privilégios profissionais foram minados, o que faz aumentar a probabilidade de que as universidades do futuro venham a ser tratadas como organizações quaisquer e seus profissionais como os demais trabalhadores.

Está claro que a mercadorização do conhecimento tem levado a novos tipos de relaçóes na academia, baseadas no que Slaughter \& Leslie chamaram de capitalismo acadêmico, e à substituição do "pro- 
Produção do conhecimento na educação superior australiana...

fessor-acadêmico" pelo "professor-empresário". Segundo Henkel (2002, p. 60): "Os cientistas acadêmicos e a instituição em que trabalham se tornaram atores mais ou menos voluntários numa série de mercados e, portanto, na mercadorização do conhecimento científico". Ela acrescenta que "a capacidade de obter lucro e a reputação intelectual constituem duas moedas de valor igualmente elevado num mercado de trabalho acadêmico cada vez mais competitivo".

Uma lição que se deve tirar do caso australiano é que o pleno potencial de um sistema de educação superior capaz de contribuir para o bem-estar, tanto social quanto econômico, da Nação não pode ser alcançado se a Nação abrir mão de seu "dever" de fomentar esse sistema de maneira adequada. Como observamos anteriormente, a tendência comum em nível internacional é que outras fontes, além do governo, assumam uma proporção maior do financiamento geral da educação superior. Na maioria dos países, todas as fontes financeiras de fomento à pesquisa têm aumentado, inclusive as do Tesouro público. Ao passo que a segunda metade dos anos de 1990 assistiu a um envolvimento maior das fontes privadas no financiamento da educação superior em vários países da OCDE, "apenas dois países, a Austrália e a Nova Zelândia, reduziram as despesas públicas diretas nesse período" (Phillips et al., 2003 , p. 3). Parece que o governo australiano, mais particularmente nestes últimos anos, quer comer seu "bolo e guardá-lo ao mesmo tempo" - quer um sistema de educação superior que contribua para o crescimento e para a prosperidade de uma sociedade e de uma economia baseadas no conhecimento, fazendo com que, cada vez mais, outros paguem por ele.

O caso australiano também sugere que o fato de a educação superior ter se ajustado ao mercado não é necessariamente deletério em si. O problema não reside tanto na introdução de medidas como a competição, o pagamento pelos usuários, a diversificação do orçamento e o incentivo empresarial, mas em como essas políticas são realmente construídas e implementadas. A introdução de mensalidades e de políticas que estimulam as instituições a encontrarem fontes alternativas de recursos no final dos anos de 1980 e no início dos anos de 1990 provavelmente permitiu que a educação superior australiana se modernizasse e alcançasse um nível de crescimento que sem isso não teria sido possível. Contudo, a partir de meados dos anos de 1990 e sob um regime político com características ideológicas diferentes, muitas das mes- 
mas políticas gerais foram utilizadas, intencionalmente ou não, para frear substancialmente o desenvolvimento do setor. Como observam Phillips et al. (2002, p. 45), o governo ainda deve enfrentar a questãochave do "nível de financiamento por estudante que um sistema de alta qualidade exige, e [de saber] até que ponto a tendência de aumentar as contribuiçóes particulares pode e deve continuar”. O problema num sistema público de educação superior como o da Austrália não é o fato de incentivar os investimentos privados, mas de abdicar da responsabilidade pública pela saúde do sistema, em vez de repartir de maneira equiitativa o peso financeiro entre todas as partes envolvidas. $\mathrm{O}$ caso australiano também levanta a questão de saber até onde o declínio da responsabilidade do governo em termos de financiamento de pesquisas pode ir sem que este perca sua autoridade "moral" sobre as políticas nacionais para a educação superior. Esperemos que ocorra uma conscientização, particularmente entre os governantes, tanto no tocante à importância de se entender o papel transformador da educação superior na sociedade quanto no que concerne à contribuição crítica da educação superior para moldar o futuro da Nação, não apenas econômica, mas também social e culturalmente. Uma visão estreita e apenas utilitária do potencial de produção de conhecimentos da academia dificilmente serve aos interesses da Nação no longo prazo.

Recebido e aprovado em setembro de 2004.

\section{Referências bibliográficas}

AUSTRALIA. Department of Education, Science and Training. National research priorities. Canberra: DEST, 2002

AUSTRALIA. Department of Education, Science and Training. Striving for quality: learning, teaching and scholarship. Canberra: DEST, 2002.

AUSTRALIA. Department of Education, Science and Training. Mapping Australian science \& innovation: final report. Canberra: McMillan, 2003.

AUSTRALIA. Department of Education, Training and Youth Affairs. Learning for life: final report of the Review of Higher Education Financing and Policy (West report). Canberra: DETYA, 1998. 
Produção do conhecimento na educação superior australiana...

AUSTRALIAN VICE-CHANCELLOR'S COMMITTEE. Major points from the ABS release Research and Experimental Development Higher Education Organisations Australia. Canberra: AVCC, 2002.

AUSTRALIAN VICE-CHANCELLOR'S COMMITTEE. Key statistics on higher education research. Canberra: AVCC, 2003a.

AUSTRALIAN VICE-CHANCELLOR'S COMMITTEE. Advancing Australia's abilities: foundations for the future of research in Australia. Canberra: AVCC, 2003b.

BACKING Australia's ability. Canberra: Commonwealth of Australia, 2001.

BERTELSEN, E. "Degrees ' $R$ ' $U s$ ”: the marketisation of the university. Disponível em: <http://web.uct.ac.za/org/aa/chomsk.htm\#Eve Bertelsen>. Acesso em: 2002.

BUCHBINDER, H. The market oriented university and the changing role of knowledge. Higher Education, v. 26, n. 3, p. 331-347, 1993.

CHUBB, I. Our universities: our future; an Australian Vice-Chancellor's Committee discussion paper. Canberra: AVCC, 2000.

CLARK, B.R. The higher education system: academic organization in crossnational perspective. Berkeley: University of California, 1983.

GALLAGHER, M. The emergence of entrepreneurial public universities in Australia. Canberra: Detya, 2000.

HENKEL, M. Current science policies and their implications for the concept of academic identity. In: WORKSHOP "Science, training and career": changing modes of knowledge production and labor markets, Oct. 21-22, 2002, Enschede. Proceedings... Enschede: CHEPS; University of Twente, 2002. p. 55-70.

HIGHER education: a policy statement. Canberra: Australian Government Printing Service, 1988.

ILLING, D. Batterham advocates funds shift. The Australian, 6 ago. 2003, p. 21.

INSIDE the knowledge factory. The Economist, Out. 2, 1997. Disponível em: <htpp://www.economist.com/surveys/showsurvey.cfm? issue= 19971004>. Acesso em: out. 2004. 
MEEK, V.L. Governance and management of Australian higher education; enemies within and without. In: Amaral, A.; Meek, V.L.; LARSEN, I.M. (Ed.). The higher education managerial revolution? Dordrecht: Kluwer, 2003. p. 179-202.

NEWMAN, F.; COUTURIER, L.; SCURRY, J. The academic marketplace: preserving higher education's soul in the age of competition. San Francisco: Jossey-Bass, 2004.

NEWSON, J. Constructing the "post-industrial" university: institutional budgeting and university corporate linkages. In: AltвACH, P.G.; Johnstone, B.D. (Ed.). The funding of higher education: international perspectives. New York: Garland, 1993. p. 285-304.

OLIVEIRA, L. Commodification of science and paradoxes in universities. Lisbon: ISCTE; University of Lisbon. Disponível em: <http:// rektorat.unizg.hr/rk/Docs/uisa.html>. Acesso em 2002.

PHILLIPS, D. et al. Independent study of the higher education review. Sage 1 Report. Byron Bay, Nsw: Phillips Curran. Disponível em: <http://www.kpac.biz>. Acesso em 2002.

PHILLIPS, D. et al. Independent study of the higher education review. Sage 2 report. Byron Bay, NSw: Phillips Curran. Disponível em: $<$ http://www.kpac.biz>. Acesso em 2003.

SCOTT, P. The changing role of the university in the production of new knowledge. Tertiary Education and Management, v. 3, n. 1, p. 5-14, 1997.

SLAUGHTER, S.; LESLIE, L. Academic capitalism: politics, policies and the entrepreneurial university. Baltimore: Johns Hopkins University, 1997.

THE SYDNEY Morning Herald, Abr. 22, 2004.

WILLMOTT, H. Commercialising higher education in the UK: the state, industry and peer review; Paper (revised version) presented at the Higher Education Close-Up Conference, July 6-8, 1998, University of Central Lancashire. 